\title{
Inpatient cardiac rehabilitation programs' exercise therapy for patients undergoing cardiac surgery: National Korean Questionnaire Survey
}

\author{
Yong Gon Seo ${ }^{1}$, Mi Ja Jang' ${ }^{2}$, Won Hah Park' ${ }^{1}$ Kyung Pyo Hong ${ }^{3}$, Jidong Sung ${ }^{3, *}$ \\ 'Division of Sports Medicine, Department of Orthopedic Surgery, Samsung Medical Center, Sungkyunkwan University School of Medicine, Seoul, Korea \\ ${ }^{2}$ Advanced Practice Nurse, Cardiac Center, Rehabilitation \& Prevention Center, Heart Vascular \& Stroke Institute, Samsung Medical Center, Seoul, Korea \\ ${ }^{3}$ Division of Cardiology, Department of Medicine, Heart Vascular \& Stroke Institute, Samsung Medical Center, Sungkyunkwan University School of Medicine, Seoul, Korea
}

Inpatient cardiac rehabilitation (ICR) has been commonly conducted after cardiac surgery in many countries, and has been reported a lots of results. However, until now, there is inadequacy of data on the status of ICR in Korea. This study described the current status of exercise therapy in ICR that is performed after cardiac surgery in Korean hospitals. Questionnaires modified by previous studies were sent to the departments of thoracic surgery of 10 hospitals in Korea. Nine replies (response rate $90 \%$ ) were received. Eight nurses and one physiotherapist completed the questionnaire. Most of the education on wards after cardiac surgery was conducted by nurses. On postoperative day 1, four sites performed sitting on the edge of bed, sit to stand, up to chair, and walking in the ward. Only one site performed that exercise on postoper- ative day 2. One activity (stairs up and down) was performed on different days at only two sites. Patients received education preoperatively and predischarge for preventing complications and reducing muscle weakness through physical inactivity. The results of the study demonstrate that there are small variations in the general care provided by nurses after cardiac surgery. Based on the results of this research, we recommended that exercise therapy programs have to conduct by exercise specialists like exercise physiologists or physiotherapists for patients in hospitalization period.

Keywords: Rehabilitation, Exercise therapy, Thoracic surgery, Questionnaires

\section{INTRODUCTION}

The cardiovascular disease mortality rate, especially ischemic heart disease (IHD), has continuously increased over the 30-year period (1983-2012) (Lee et al., 2015). IHD mortality rises sharply with age and remains the leading cause of death (Finegold et al., 2013) and coronary artery bypass graft (CABG) is one of the therapies generally performed for coronary revascularization in IHD patients (Keenan et al., 2005). However, a variety of complications including pulmonary complications (pneumonia, pleural effusion, atelectasis) and arrhythmia (atrial fibrillation, atrial flutter) can occur after CABG (European Heart Rhythm Association et al., 2010; Pasquina et al., 2003). In addition, even after revascularization through operation, the restenosis rate reportedly ranges from 5.9\%-11.5\% (Sumide et al., 2009).

After cardiac surgery, ICR contributes significantly to the prevention of lung complication and decondition caused by prolonged bed rest, thus to early recovery (Stiller et al., 1994). Cardiac rehabilitation is a multidisciplinary program that includes medical treatment, nutritional counseling, smoking cessation, risk factor intervention, stress management, and exercise therapy (Mampuya, 2012), among which exercise therapy is the essential component. ICR is mainly composed of breathing exercises, early mobilization, and strength exercises (Shaw et al., 1989; Westerdahl et al., 2005). Exercise therapy improves exercise capacity by about 16\% (Maines et al., 1997). When the exercise capacity improves by one metabolic equivalent, all-cause mortality decreases 12\% (Myers et al., 2002). In addition, regular exercise decreases
${ }^{*}$ Corresponding author: Jidong Sung (D) http://orcid.org/0000-0002-1006-5727 Division of Cardiology, Department of Medicine, Heart Stroke \& Vascular Institute, Samsung Medical Center, Sungkyunkwan University School of Medicine, 81 Irwonro, Gangnam-gu, Seoul 06351, Korea

Tel: +82-2-3410-2853, Fax: +82-2-3410-2853, E-mail: Jidong.sung@samsung.com Received: October 1, 2016 / Accepted: January 6, 2017
This is an Open Access article distributed under the terms of the Creative Commons Attribution Non-Commercial License (http://creativecommons.org/licenses/by-nc/4.0/) which permits unrestricted non-commercial use, distribution, and reproduction in any medium, provided the original work is properly cited. 
all-cause mortality by $28 \%$, which is closely associated with improvements in quality of life (Clark et al., 2005).

Most previous studies (Anderson et al., 2016; Choo et al., 2007; Kim et al., 2011; Lee et al., 2016) on cardiac rehabilitation, especially exercise therapy, were conducted a focus on applying exercise programs to specific parameters. There has been no national study survey showing the actual practice after cardiac surgery performed in general hospitals. Several studies abroad (Filbay et al., 2012; Overend et al., 2010; Westerdahl and Möller, 2010; Westerdahl and Olsén, 2011) published surveys of the current practice of ICR in each nation presenting baseline data with which ICR systems between countries can be compared. According to domestic research (Song, 2009) that evaluated outpatient cardiac rehabilitation programs, cardiac rehabilitation practiced in Korea varies in methods, durations, and teams. Intervention contents are also reportedly practiced in many forms depending on subjects. In reality, there is no current baseline data for comparative analysis on the ICR systems of domestic hospitals. Therefore, this study attempted to understand the status of the inpatient postoperative care systems of South Korea's general hospitals practicing cardiac surgery (i.e., those awarded first class status in the adequacy assessment by Health Insurance Review \& Assessment Service). This study will provide baseline data for upgrading exercise-based ICR programs.

\section{MATERIALS AND METHODS}

Ten first class CABG hospitals noted by South Korea's Health Insurance Review \& Assessment Service in 2011 (Samsung Medical Center, Asan Medical Center, Seoul National University Hospital, Seoul National University Bundang Hospital, Gangnam Severance Hospital, Severance Hospital, Ajou University Medical Center, Konkuk University Medical Center, Catholic University Hospital, Sejong Hospital) were selected for survey. The survey was conducted by emailing a questionnaire to the thoracic and cardiovascular surgery departments of each hospital. Comparative analysis was performed with nine hospitals who responded to the questionnaires. Cardiac surgery was defined as CABG or valve surgery in which median sternotomy was performed. Nurses and physiotherapist caring for patients after cardiac surgery returned the questionnaire written for this study.

The questionnaire was developed to question the typical process of a postoperative ward (Appendix 1). The survey information was developed by modifying the survey of previous studies (Firouzabadi et al., 2014; Overend et al., 2010) to focus on the purpose of this study. To verify validity of the completed questionnaire, one professor at S University Hospital, one advanced practice nurse of thoracic surgery and five ward nurses of thoracic surgery independently evaluated questionnaire items to verify questionnaire content validity. At this time, unrealistic and unclear items were deleted and more appropriate questions were added to modify the questionnaire. The study was conducted from December 2012 to February 2013. The completed questionnaire was sent to the 10 hospitals via e-mail and the returned questionnaires from nine hospitals were used for study analysis. This study received ethical approval from the Internal Review Board of Samsung Medical Center prior to this research (approval number: 2013-02-124).

Data were analyzed using descriptive statistics and expressed using means, medians, and ranges. IBM SPSS Statistics ver. 20.0 (IBM Co., Armonk, NY, USA) was used for analysis of the study data.

\section{RESULTS}

The study was conducted with nine hospitals responding to a questionnaire survey e-mailed to 10 hospitals identified as first class CABG hospitals by Health Insurance Review \& Assessment Service in 2011. These nine hospitals practiced CABG and valve surgery. A ward nurse conducted postoperative systematic exercise education in seven hospitals. The respondents were nurses in departments of thoracic surgery with at least 6 years of experience in 8 out of 9 cases. On average, 18.2 cases of cardiac surgery were performed per week and the postoperative hospital stay was 8.8 days (Table 1).

Evaluation of cardiopulmonary function was practiced in five hospitals preoperatively (56\%) and education on deep breathing and coughing was provided in eight hospitals preoperatively $(89 \%)$. Evaluation of sustained maximal inspiration was practiced in seven hospitals $(78 \%)$ and education on incentive spirometry in eight hospitals (89\%) preoperatively. However, the seven hospitals $(33 \%)$ did not practice postoperative manual therapy (Table 2).

Education on postoperative mobility was practiced in all nine hospitals. While eight hospitals practiced education on sternal precautions before exercise, one hospital did not. Postoperative

Table 1. Demographic of cardiac surgery

\begin{tabular}{lc}
\hline Characteristic & Mean (range) \\
\hline Cardiac surgery beds $(\mathrm{n})$ & $70(11-188)$ \\
Cardiac surgeons (n) & $3.8(2-5)$ \\
Surgeries/wk (n) & $18.2(5-70)$ \\
Length of stay (day) & $8.8(5-14)$ \\
\hline
\end{tabular}


Seo YG, et al. • Questionnaire survey of exercise-based inpatient cardiac rehabilitation programs

Table 2. The education of physiotherapy before and after cardiac surgery

\begin{tabular}{|c|c|c|c|c|c|c|}
\hline Education of physiotherapy & Pre & POD 1 & POD 3 & POD 5 & POD 7 & None \\
\hline CR assessment & $5(56)$ & $1(11)$ & $1(11)$ & - & $2(22)$ & - \\
\hline $\mathrm{DB} \& \mathrm{C}$ & $8(89)$ & $1(11)$ & - & - & - & - \\
\hline SMl & $7(78)$ & $1(11)$ & - & - & - & $1(11)$ \\
\hline IS & $8(89)$ & $1(11)$ & - & - & - & - \\
\hline MT & - & - & - & 2 (22) PRN & - & $7(78)$ \\
\hline
\end{tabular}

Values are presented as number of hospitals (\%).

CR, cardiac rehabilitation; DB \& C, deep breathing \& coughing; SMI, sustain maximal inspiration; IS, incentive spirometer; MT, manual therapy; PRN, as necessary; POD, postoperative day.

Table 3. Rate of physical activity at each day after cardiac surgery

\begin{tabular}{|c|c|c|c|c|c|c|c|}
\hline Physical activity & POD & POD 1 & POD 2 & POD 3 & POD 4 & POD 5 & None \\
\hline Bed mobility only & $4(45)$ & $3(33)$ & $1(11)$ & $1(11)$ & - & - & - \\
\hline Sitting on edge of bed & - & $8(89)$ & $1(11)$ & - & - & - & - \\
\hline Sit to stand by bed & - & $7(78)$ & $2(22)$ & - & - & - & - \\
\hline Sit to stand by chair & - & $6(67)$ & $2(22)$ & $1(11)$ & - & - & - \\
\hline Walking in the ward & - & $6(67)$ & $2(22)$ & $1(11)$ & - & - & - \\
\hline Walking in the corridor & - & $3(33)$ & $2(22)$ & $3(33)$ & $1(11)$ & - & - \\
\hline Stairs up and down & - & - & - & - & - & $2(22)$ & $7(78)$ \\
\hline Corridor walking frequency & - & $4(44)$ & $5(56)$ & - & - & - & - \\
\hline
\end{tabular}

Values are presented as number of hospitals (\%).

POD, postoperative day.

bed rest was practiced most on postoperative day (POD) 1 (33\%) and on POD 3 in one hospital (11\%). Patient's sitting on the edge of bed was practiced on POD 1 (89\%) in eight hospitals while sit to stand by bed was practiced on POD $1(78 \%)$ in seven hospitals and on POD $2(22 \%)$ in two hospitals. Sit to stand by chair was practiced on POD $1(68 \%)$ in six hospitals. Walking in the ward was practiced most on POD 1 (68\%) and walking in the corridor was most frequently practiced on PODs 1 and 3 with $33.3 \%$, respectively. Stairs up and down, the final ward exercise therapy, was practiced in only two hospitals (22\%) (Table 3).

Ward and discharge education were practiced in eight hospitals (89\%) and six hospitals (67\%), respectively. Education methods mainly included face-to-face $(67 \%)$ and brochure education (22\%). Ward education content included hospitalization guides, disease education, educations after general admission, intensive care unit/subintensive care unit education, breathing exercises, and walking exercises, occupying $67 \%$. A high proportion of the discharge education content was occupied by management of surgery sites $(67 \%)$, taking medication (56\%), and sternal precautions (56\%); there was less education on exercise therapy such as walking exercise programs (22\%), stretching and strengthening exercises (44\%), and introduction to cardiac rehabilitation and community associations (22\%) (Fig. 1).

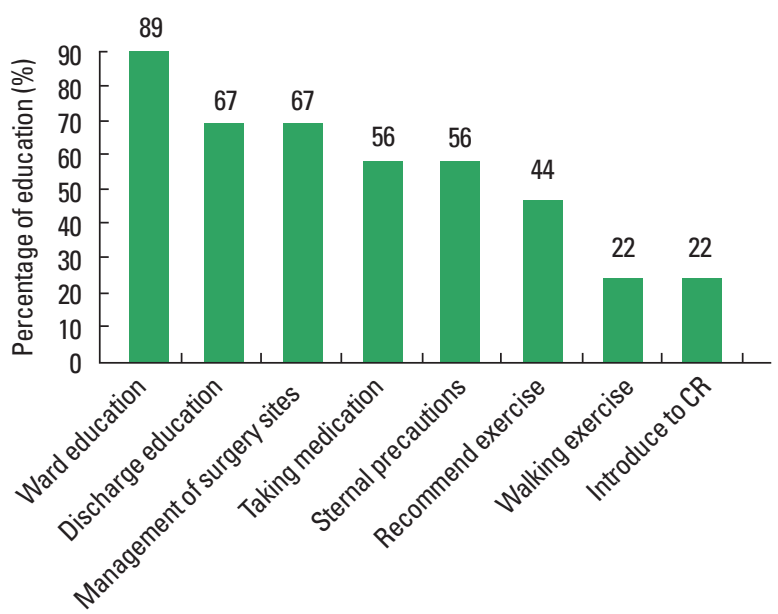

Fig. 1. The categorization and distribution of patient education that conducted in ward and predischarge. This figure shows that the education, which is walking exercise and introduce to cardiac rehabilitation (CR), for enhancing exercise compliance has not recommended compare with other variables.

\section{DISCUSSION}

This study is the first survey study to describe ICR practiced by South Korea's tertiary care hospitals. A questionnaire with 29 items was e-mailed to 10 hospitals designated as first class CABG 
Table 4. Comparison between present study and previous articles for cardiac rehabilitation

\begin{tabular}{|c|c|c|c|}
\hline \multirow{2}{*}{ Variable } & \multicolumn{3}{|c|}{ Study } \\
\hline & Overend et al. & Westerdahl et al. & Present \\
\hline Country & Canada & Sweden & Korea \\
\hline Year of study & 2010 & 2010 & 2013 \\
\hline Sample size, hospital (respondent) & $18(18)$ & $8(29)$ & $9(9)$ \\
\hline Respondent & Physiotherapist & Physiotherapist & Nurses, physiotherapist \\
\hline Response rate (\%) & 100 & 88 & 90 \\
\hline Data collection & Telephone survey & Postal survey & E-mail survey \\
\hline No. of surgeries/wk, mean (range) & $21(6-24)$ & Not collected & $18.7(5-70)$ \\
\hline LOS (day), mean (range) & $6.4(4-10.6)$ & Not collected & $8.8(5-14)$ \\
\hline Sit to stand by bed* & POD 1 (94\%) & POD 1 (97\%) & POD 1 (78\%) \\
\hline Sit to stand by chair* & POD 1 (50\%) & POD 1 (97\%) & POD 1 (67\%) \\
\hline Walking in the ward* & POD 1 (22\%) & POD 2 (79\%) & POD 1 (33\%) \\
\hline Walking in the corridor* & POD $2(50 \%)$ & POD $3(93 \%)$ & POD $3(33 \%)$ \\
\hline Stairs up and down* & Not collected & POD 4 (38\%) & POD $5(23 \%)$ \\
\hline
\end{tabular}

LOS, length of stay; POD, postoperative day.

*The highest percentage of each exercise between first and fifth postoperative days.

hospitals by Health Insurance Review \& Assessment Service and replies were received from nine hospitals.

Physical activity is generally recommended for lung complication prevention and quality of life improvement after cardiac surgery (Firouzabadi et al., 2014). In the hospitals surveyed in this study, education on postoperative deep breathing and cough techniques, sustain maximal inspiration, and incentive spirometer (IS) was initially practiced. According to a previous study by Overend et al. (2010), education on deep breathing and cough techniques was practiced on PODs $1(89 \%)$ and $2(78 \%)$, respectively, while IS education was on PODs 1 (44\%) or $2(39 \%)$. In this study, all participating hospitals (100\%) practiced education on deep breathing and cough techniques preoperatively and five hospitals practiced another time on POD 1. This is similar to the report of Westerdahl and Olsén (2011) in which education on preoperative breathing exercises and cough techniques was completed $88 \%$ of the time. From these results, ward nurses are recognizing breathing exercises and cough techniques as very important factors in postoperative patients' functional recovery and the importance of preoperative and POD 1 is especially emphasized.

Restarting physical activity in the early period after cardiac surgery, especially walking exercise, is recommended since it can prevent complications from long-term bed rest. While physical activity from postoperative bed rest to walking in the corridor was practiced in all hospitals, stairs up and down was practiced only in four hospitals. Exercise education was conducted in seven hospitals mostly by face-to-face education with a nurse from the inten- sive care unit. In two hospitals, exercise education was practiced by an exercise physiologist along with a nurse. In most of the previous studies (Filbay et al., 2012; Overend et al., 2010; Westerdahl and Möller, 2010; Westerdahl and Olsén, 2011), sitting on the edge of the bed and sit to stand were reportedly practiced on POD 1. In this study, sitting on the edge of the bed was practiced on POD 1 in eight hospitals (89\%), while walking in the ward and walking in the corridor were practiced on PODs 2 and 3 , respectively. However, the stairs up and down exercise was only practiced in two out of nine hospitals.

Although education encouraged progress as far as walking in the corridor, exercise at the next level of strength was not practiced afterwards. This can be the result of the differences in the ICR systems where exercise therapy for cardiac rehabilitation is practiced by physiotherapists in foreign countries. In foreign countries (Table 4), physiotherapists in intensive care units implement all education on rehabilitation after cardiac surgery whereas in Korea, ward nurses initially complete it. In Korea, during the postoperative admission period, participation in exercise education of exercise specialists and physiotherapists is poor for cardiac rehabilitation. Participation of exercise specialist cooperating with ward nurses in the ICR may help to facilitate the process of progressive ambulation and thus less deconditioning and faster recovery.

In addition, preadmission ward and predischarge education were conducted in most hospitals. Ward education was mainly composed of the hospitalization guide and breathing exercises; walking exercises were the only education that emphasized the 
importance of postoperative exercise. A high proportion of before-discharge education content addressed management of surgery sites, taking medications, and sternal precautions. According to Overend et al. (2010), 11 out of the 18 hospitals (61\%) reportedly offered walking programs, upper and lower extremity exercises and stretching, introduction to cardiac rehabilitation, sternal precautions, and physical activity guidelines as before-discharge education. In this study, with walking exercise programs (22\%), stretching and strength exercises (44\%), and introduction to cardiac rehabilitation (22\%) as before-discharge education, the ratio of exercise therapy education was less than that in foreign cases. Exercise therapy after cardiac surgery plays an important role in improving patients' exercise capacity and quality of life (Firouzabadi et al., 2014; Maines et al., 1997). In the hospitals that participated in this study, there was an education content deficit on the importance of exercise in before-discharge education. The contents of the education should be revised to fill this gap and again participation of exercise specialists in the process may be helpful.

This study has some limitations. First, the surveyed hospitals were limited to 10 first class hospitals designated by Health Insurance Review \& Assessment Service. Even if not first class, there could be hospitals with well-built postoperative cardiac rehabilitation systems. Therefore, the study result may not represent all Korean hospitals. Second, the questionnaire was composed by modifying a previous study's survey; only the survey items related to the study purpose and specific topics were used. For example, while sternal precaution was described in detail and augmented in foreign survey studies, only its practice was surveyed in this study. Third, the respondent from each hospital was only one person. Either a nurse of thoracic surgery or a physiotherapist participated in the survey. One physiotherapist answered our questionnaire because one hospital conducted an exercise education by physiotherapist before discharge. Further study needs to survey conducted to various caring staff who works in the ward for patient with recovering from cardiac surgery in same hospital. Fourth, surveys on indicators from the patients' position, such as patient satisfaction or quality of life, were not performed.

In conclusion, this study is the first survey report on ICR practiced domestically after cardiac surgery. The main difference in program compared to the foreign hospitals in the exercise therapy, both in the degree of progression and educational contents. Overall lack of participation of exercise specialists or physiotherapists seems to be an important difference. This study may be an initiative in refining ICR program in Korea. A nationwide survey including more hospitals of all levels is necessary.

\section{CONFLICT OF INTEREST}

No potential conflict of interest relevant to this article was reported.

\section{ACKNOWLEDGMENTS}

The data obtained from this study has supported by nine different hospitals in 2013. We thank all respondents who replayed the questionnaire for this research.

\section{REFERENCES}

Anderson L, Oldridge N, Thompson DR, Zwisler AD, Rees K, Martin N, Taylor RS. Exercise-Based Cardiac Rehabilitation for Coronary Heart Disease: Cochrane Systematic Review and Meta-Analysis. J Am Coll Cardiol 2016;67:1-12.

Choo J, Burke LE, Pyo Hong K. Improved quality of life with cardiac rehabilitation for post-myocardial infarction patients in Korea. Eur J Cardiovasc Nurs 2007;6:166-171.

Clark AM, Hartling L, Vandermeer B, McAlister FA. Meta-analysis: secondary prevention programs for patients with coronary artery disease. Ann Intern Med 2005;143:659-672.

European Heart Rhythm Association; European Association for Cardio-Thoracic Surgery, Camm AJ, Kirchhof P, Lip GY, Schotten U, Savelieva I, Ernst S, Van Gelder IC, Al-Attar N, Hindricks G, Prendergast B, Heidbuchel H, Alfieri O, Angelini A, Atar D, Colonna P, De Caterina R, De Sutter J, Goette A, Gorenek B, Heldal M, Hohloser SH, Kolh P, Le Heuzey JY, Ponikowski P, Rutten FH. Guidelines for the management of atrial fibrillation: the Task Force for the Management of Atrial Fibrillation of the European Society of Cardiology (ESC). Eur Heart J 2010;31:2369-2429.

Filbay SR, Hayes K, Holland AE. Physiotherapy for patients following coronary artery bypass graft (CABG) surgery: limited uptake of evidence into practice. Physiother Theory Pract 2012;28:178-187.

Finegold JA, Asaria P, Francis DP. Mortality from ischaemic heart disease by country, region, and age: statistics from World Health Organisation and United Nations. Int J Cardiol 2013;168:934-945.

Firouzabadi MG, Sherafat A, Vafaeenasab M. Effect of physical activity on the life quality of coronary artery bypass graft patients. J Med Life 2014;7:260-263.

Keenan TD, Abu-Omar Y, Taggart DP. Bypassing the pump: changing practices in coronary artery surgery. Chest 2005;128:363-369.

Kim C, Kim DY, Moon CJ. Prognostic influences of cardiac rehabilitation in korean acute myocardial infarction patients. Ann Rehabil Med 
2011;35:375-380.

Lee J, Song Y, Lindquist R, Yoo Y, Park E, Lim S, Chung Y, Mathiason MA. Nontraditional Cardiac Rehabilitation in Korean Patients with Coronary Artery Disease. Rehabil Nurs 2016 Apr 14 [Epub]. https:// doi.org/10.1002/rnj.268.

Lee SW, Kim HC, Lee HS, Suh I. Thirty-year trends in mortality from cardiovascular diseases in Korea. Korean Circ J 2015;45:202-209.

Maines TY, Lavie CJ, Milani RV, Cassidy MM, Gilliland YE, Murgo JP. Effects of cardiac rehabilitation and exercise programs on exercise capacity, coronary risk factors, behavior, and quality of life in patients with coronary artery disease. South Med J 1997;90:43-49.

Mampuya WM. Cardiac rehabilitation past, present and future: an overview. Cardiovasc Diagn Ther 2012;2:38-49.

Myers J, Prakash M, Froelicher V, Do D, Partington S, Atwood JE. Exercise capacity and mortality among men referred for exercise testing. N Engl J Med 2002;346:793-801.

Overend TJ, Anderson CM, Jackson J, Lucy SD, Prendergast M, Sinclair S. Physical therapy management for adult patients undergoing cardiac surgery: a canadian practice survey. Physiother Can 2010;62:215-221.

Pasquina P, Tramèr MR, Walder B. Prophylactic respiratory physiotherapy after cardiac surgery: systematic review. BMJ 2003;327:1379.

Shaw DK, Deutsch DT, Bowling RJ. Efficacy of shoulder range of motion exercise in hospitalized patients after coronary artery bypass graft surgery. Heart Lung 1989;18:364-369.

Song Y. Analyses of studies on cardiac rehabilitation for patients with cardiovascular disease in Korea. J Korean Acad Nurs 2009;39:311-320.

Stiller K, Montarello J, Wallace M, Daff M, Grant R, Jenkins S, Hall B, Yates $\mathrm{H}$. Efficacy of breathing and coughing exercises in the prevention of pulmonary complications after coronary artery surgery. Chest 1994;105:741-747.

Sumide T, Shimada K, Ohmura H, Onishi T, Kawakami K, Masaki Y, Fukao K, Nishitani M, Kume A, Sato H, Sunayama S, Kawai S, Shimada A, Yamamoto T, Kikuchi K, Amano A, Daida H. Relationship between exercise tolerance and muscle strength following cardiac rehabilitation: comparison of patients after cardiac surgery and patients with myocardial infarction. J Cardiol 2009;54:273-281.

Westerdahl E, Lindmark B, Eriksson T, Friberg O, Hedenstierna G, Tenling A. Deep-breathing exercises reduce atelectasis and improve pulmonary function after coronary artery bypass surgery. Chest 2005;128: 3482-3488.

Westerdahl E, Möller M. Physiotherapy-supervised mobilization and exercise following cardiac surgery: a national questionnaire survey in Sweden. J Cardiothorac Surg 2010;5:67.

Westerdahl E, Olsén MF. Chest physiotherapy and breathing exercises for cardiac surgery patients in Sweden--a national survey of practice. Monaldi Arch Chest Dis 2011;75:112-119. 


\section{Appendix 1. Questionnaire}

Title: Inpatient cardiac rehabilitation programs' exercise therapy for patients undergoing cardiac surgery: National Korean questionnaire survey Purpose: This study attempted to understand the status of the inpatient postoperative care systems of South Korea's general hospitals practicing cardiac surgery. This study will also provide baseline data for upgrading exercise-based inpatient cardiac rehabilitation programs.

\section{Hospital state}

1. How many beds for patients with cardiac surgery do you have in your hospital? 2. How many surgeons are in your department of Thoracic Surgery?

3. How many surgeries are performed per week in your unit?

4. How many days are stay in hospital after surgery Valve

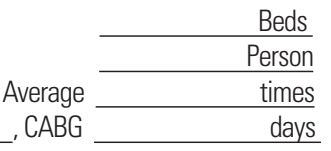

\section{Evaluation}

5. Which of the following days do you usually evaluate patients for pulmonary function?
$\square$ Preop $\square$ POD
$\square$ POD 1
$\square$ POD 2
$\square$ POD 3
$\square$ POD 4
$\square$ POD 5
$\square$ POD $\square \mathrm{N} / \mathrm{A}$

6. Which of the following days do you usually educate patients to deep breathing and coughing?
$\square$ Preop $\square$ POD
$\square$ POD 1
$\square$ POD 2
$\square$ POD 3
$\square$ POD 4
POD 5
POD

7. Which of the following days do you usually educate patients to sustained maximal inspiration?
$\square$ Preop
$\square \mathrm{POD}$
$\square$ POD 1
$\square$ POD 2
$\square$ POD 3
$\square$ POD 4
$\square$ POD $5 \square$ POD
$\square$ N/A

8. Which of the following days do you usually educate patients to incentive spirometry?
$\square$ Preop
$\square$ POD
$\square$ POD 1
$\square$ POD 2
$\square$ POD 3
$\square$ POD 4
$\square$ POD 5
$\square \mathrm{POD} \quad \square \mathrm{N} / \mathrm{A}$

9. Which of the following days do you usually perform a manual techniques for patients?

$\square$ Preop $\square$ POD $\square$ POD1 $\square$ POD2 $\square$ POD3 $\square$ POD4 $\square$ POD5 $\square$ POD $\square$ N/A

\section{Physical activity}

10. How many days are in bed rest after surgery?

$\square$ Preop $\square$ POD $\square$ POD1 $\square$ POD2 $\square$ POD3 $\square$ POD4 $\square$ POD5 $\square$ POD $\square$ N/A

11. When is patients usually instructed to perform a "sitting on edge of bed"?

$\square$ Preop $\square$ POD $\square$ POD1 $\square$ POD2 $\square$ POD3 $\square$ POD4 $\square$ POD5 $\square$ POD $\square$ N/A

12. When does the patients perform a "sit to stand by bed"?

$\square$ Preop $\square$ POD $\square$ POD1 $\square$ POD2 $\square$ POD3 $\square$ POD4 $\square$ POD5 $\square$ POD $\square$ N/A

13. When is patients usually instructed to perform a "sit to stand by chair"?

$\square$ Preop $\square$ POD $\square$ POD1 $\square$ POD2 $\square$ POD3 $\square$ POD4 $\square$ POD5 $\square$ POD $\square$ N/A

14. When is patients usually instructed to perform a "walking in the ward"?

$\square$ Preop $\square$ POD $\square$ POD1 $\square$ POD2 $\square$ POD3 $\square$ POD4 $\square$ POD5 $\square$ POD $\square$ N/A

15. When is patients usually instructed to perform a "walking in the corridor"?

$\square$ Preop $\square$ POD $\square$ POD1 $\square$ POD2 $\square$ POD3 $\square$ POD4 $\square$ POD5 $\square$ POD $\square$ N/A

16. When is patients usually instructed to perform a "stairs up and down"?

$\square$ Preop $\square$ POD $\square$ POD1 $\square$ POD2 $\square$ POD3 $\square$ POD4 $\square$ POD5 $\square$ POD $\square$ N/A

17. How many times per day are patients usually instructed to perform a "walking in the corridor"?

$\square 1 \quad \square 2 \quad \square 3 \quad \square$ Above $4 \square$ N/A

18. How many frequents per day are patients usually instructed to exercise education?

$\square 1 \quad \square 2 \quad \square 3 \quad \square$ Above $4 \square \mathrm{N} / \mathrm{A}$ 
Appendix 1. Continued from the previous page

\section{Sternal precaution}

19. Do you have an education to sternal precaution for patients?

$\square$ Yes $\square$ No

20. If yes, when is patients usually educated to sternal precaution?

$\square$ Preop $\square$ POD $\square$ POD1 $\square$ POD2 $\square$ POD3 $\square$ POD4 $\square$ POD5 $\square$ POD $\square$ N/A

\section{Preadmission ward and predischarge education}

21. Do you have a pre-admission ward education?

$\square$ Yes $\square$ No

22. If yes, what type of education method do you usually use?

$\square$ Face to face $\square$ Brochure $\square$ VOD $\square$ Internet $\square$ Etc.,

23. When the preadmission ward education is instructed to the patients?

$\square$ Preop $\square$ POD $\square$ POD1 $\square$ POD2 $\square$ POD3 $\square$ POD4 $\square$ POD5 $\square$ POD $\square$ N/A

24. Please check the box of the following educations you usually provide to the patients in the pre-admission?

$\square$ Hospitalization guide $\square$ Disease education $\square$ Education after general admission

$\square$ Intensive care unit(ICU)/sub-ICU education $\square$ Breathing exercises $\square$ Walking exercises

$\square$ Pain control $\square$ Diet therapy $\square$ Prevention of complication $\square$ Etc.,

25. Do you have a pre-discharge education program and brochure?

$\square$ Yes $\square$ No

26. If yes, Please check the box of the following educations you usually provide to the patients in the predischarge.

$\square$ Walking exercise program $\quad \square$ Management of surgery sites $\quad \square$ Stretching and strengthening exercises

$\square$ Taking medication $\quad \square$ Procedure for discharge $\quad \square$ Sternal precaution

$\square$ Introduction to cardiac rehabilitation and community associations $\square$ Etc.,

27. What is your occupation?

$\square$ Physician $\square$ Nurse $\square$ Physiotherapist $\square$ Exercise specialist $\square$ Etc.

28. What department are you in?

$\square$ Thoracic surgery $\quad \square$ Cardiology $\square$ Physical \& medicine rehabilitation $\square$ Etc.,

29. How many years have you been working in your department?
$\square 1-3$ years
$\square$ 3-6 years
$\square$ 6-9years
$\square 9-10$ years
$\square$ Above 10 years years

Thank you for your response to this questionnaire. 